\title{
Use of the spinal board within the accident and emergency department
}

\author{
Matthew W Cooke
}

\begin{abstract}
A postal questionnaire was sent to all consultants and specialist trainees in the West Midlands about the use of spinal boards in the accident and emergency (A\&E) department. Response rate was $70 \%$. There was widespread use of boards in A\&E despite an ATLS recommendation to the contrary. Hospitals should review their policies on use of spinal boards within the department, using the evidence available to determine the best means of immobilisation.

( Accid Emerg Med 1998;15:108-109)
\end{abstract}

Keywords: spinal boards

The role of the spinal board within the accident and emergency (A\&E) department has been challenged recently. ${ }^{1}$ It was originally developed as an extrication device using its smooth surface to allow a person to be slid out of a vehicle. However, it is difficult to remove him from the board in the field and therefore the patient is most commonly transported to the A\&E department on the spinal board. The non-conforming nature of the board means that pressure points are exposed to high interface pressures ${ }^{2}$ and there is a risk of pressure sores developing. In addition, the shape of the board does not conform to the shape of the spine.

Alternatives include the vacuum splint, which provides better immobilisation of the trunk with less slippage on a gradual lateral tilt; the backboard with head blocks, which is slightly better at immobilising the head ${ }^{3}$; and the vacuum mattress, which has disadvantages in prehospital use but may be preferable in hospital. ${ }^{4}$

The aim of this study was to determine how spinal boards are used within the A\&E depart-

\begin{tabular}{|c|c|c|c|}
\hline \multirow{2}{*}{$\begin{array}{l}\text { Accident and } \\
\text { Emergency Medicine, } \\
\text { University of } \\
\text { Birmingham and City } \\
\text { Hospital NHS Trust, } \\
\text { Birmingham, UK } \\
\text { M W Cooke }\end{array}$} & \multicolumn{3}{|c|}{$\begin{array}{l}\text { The aim of this study was to determine how } \\
\text { spinal boards are used within the A\&E depart- }\end{array}$} \\
\hline & & No & $\%$ \\
\hline $\begin{array}{l}\text { Correspondence to: } \\
\text { M W Cooke, A\&E } \\
\text { Department, City Hospital, } \\
\text { Dudley Road, Birmingham } \\
\text { B18 7QH, UK; email } \\
\text { M.W.COOKE@bham.ac.uk }\end{array}$ & $\begin{array}{l}\text { Early in primary survey } \\
\text { After initial } x \text { rays } \\
\text { After } x \text { ray and log roll } \\
\text { When spinal injury excluded } \\
\text { After log roll } \\
\text { After secondary survey } \\
\text { After computerised tomography } \\
\text { After definitive care }\end{array}$ & $\begin{array}{r}2 \\
2 \\
22 \\
1 \\
3 \\
3 \\
1 \\
1\end{array}$ & $\begin{array}{r}6 \\
6 \\
63 \\
3 \\
9 \\
9 \\
3 \\
3\end{array}$ \\
\hline
\end{tabular}

ment, with particular reference to the time when the patient is removed from the board and the primary use of boards within the department.

\section{Methods}

A postal questionnaire was sent to all $A \& E$ consultants and specialist trainees in the West Midlands. Seventy per cent (35 of 50) returned the questionnaire. Anonymity was preserved, so there was no follow up of non-responders. Respondents were asked six open questions relating to their use of spinal boards within the A\&E department.

\section{Results}

Thirty one respondents (88\%) had a spinal board in the department.

If a patient was brought to the $A \& E$ department on a spinal board he would be removed at a variety of stages in the resuscitation process. These are listed in table 1 . The majority (32, $91 \%$ ) would not be removed until at least after completion of the primary survey, initial resuscitation, and first line $x$ rays.

The preferred method of immobilisation within the A\&E department was the spinal board in conjunction with a collar and side support of the head. This was used by 15 respondents (43\%). Eleven (31\%) stated that a spinal board was the preferred method but did not specify use of other adjuncts. Five (14\%) preferred immobilisation on the A\&E department trolley with collar and side support.

In order to transfer a patient from bed to bed or from bed to scanner, various methods were in use. Eighteen (51\%) stated they would use a spinal board, nine $(26 \%)$ a controlled lift, three $(9 \%)$ either a lift or a board, one $(3 \%)$ a stretcher canvas, and two (6\%) either a scoop stretcher or board.

A patient not already on a board would be put on a board in the $A \& E$ department if there was a high risk of injury $(18,51 \%)$, if they had a known spinal injury $(2,6 \%)$, or for transfer to another department or hospital $(4,12 \%)$. Nine respondents $(26 \%)$ said they would never put a patient on a board after they had arrived in the A\&E department.

When questioned on problems related to spinal boards, 18 quoted the risk of pressure sores and 20 that boards were uncomfortable. Other problems quoted included giving a false 
sense of security (4), difficulty moving the patient on a board (4), inappropriate use of the board (4), the non-conforming nature of the board (4), preventing proper examination (3), and scaring the patient (2).

\section{Discussion}

There is widespread use of spinal boards within the A\&E department. Advanced Trauma Life Support (ATLS) clearly states that the long board is for use "before and during transfer" and not for use within the A\&E department. This survey reveals that senior staff are well aware of the risks of spinal boards. However, boards remain the preferred method of immobilisation despite evidence that other surfaces are less hazardous and possibly give better support. ${ }^{2}$ The reasons for preference of the spinal board are not clear.

It is understandable that if a patient is brought to $A \& E$ on a spinal board then initial resuscitation should take priority over removal from the board. However, many clinicians delay removal well beyond this time. Even the best boards will affect the quality of $x$ rays taken through them-another reason for re- moval before the end of the primary survey. The patient will often have been on the board for at least 15-30 minutes before arrival in the $\mathrm{A} \& \mathrm{E}$ department and therefore tissue damage may already be occurring. Many place the patient on a board after arrival in A\&E. In these circumstances, the use of a vacuum mattress would be preferable. It may be that ATLS has introduced people to the spinal board but has not made them sufficiently aware of their problems or the alternatives available.

Hospitals should review their policies on use of spinal boards within the department using the evidence available to determine the best means of immobilisation within the $A \& E$ department.

1 Cooke MW. Spinal boards in A\&E. J Accid Emerg Med 1996;13:433.

2 Main PW, Lovell ME. A review of seven support surfaces with emphasis on their protection of the spinally injured. J Accid Emerg Med 1996;13:34-7.

3 Johnson DR, Hauswald M, Stockhoff C. Comparison of a vacuum splint device to a rigid backboard for spinal immobilisation. Am J Emerg Med 1996;14:369-72.

4 Carney C. Support surfaces. J Accid Emerg Med 1996;13: 302.

5 American College of Surgeons Advanced Trauma Life Support. Chicago: ACS, 1993.

\section{Relatives in the resuscitation room: their point of view}

F Barratt, D N Wallis

\section{Accident and}

Emergency

Department, Guy's and St Thomas' Trust,

London SE1

F Barratt

D N Wallis

Correspondence to: Dr F Barratt, Accident and Emergency Department,

University Hospital

Lewisham, Lewisham High

St, London SE13 6LH, UK.

Accepted for publication 22 October 1997

\begin{abstract}
Objective-To investigate whether bereaved next of kin would like to have been present in the resuscitation room during attempted cardiopulmonary resuscitation of their relative, and their experience or knowledge of what is involved in cardiopulmonary resuscitation.

Methods-The next of kin of patients who had recently died after unsuccessful cardiopulmonary resuscitation in the accident and emergency department were contacted initially by telephone and then sent a postal questionnaire.

Results-Four (11\%) of 35 respondents had been asked whether they wished to be present in the resuscitation room; 24 $(69 \%)$ would like to have been offered the opportunity, even though not all would have accepted. The respondents had a wide variety of perceptions of what happens during resuscitation, few of which corresponded to clinical practice.

Conclusions-Most relatives of patients requiring cardiopulmonary resuscitation would like to be offered the possibility of being in the resuscitation room; this could have several benefits.

$(\Im$ Accid Emerg Med 1998;15:109-111)
\end{abstract}

Keywords: relatives; cardiopulmonary resuscitation; resuscitation room
There has been recent debate ${ }^{1-3}$ over the presence of relatives in the resuscitation room, not only the parents of children but also relatives of adult patients. Most research has concentrated on the attitudes and feelings of medical and nursing staff, ${ }^{45}$ and in one study ${ }^{4}$ $75 \%$ of medical and nursing staff agreed with the statement, "Relatives should have the opportunity to be with a family member who is requiring cardiopulmonary resuscitation, provided appropriate professional support is available." By contrast little has been published on the attitude of recently bereaved relatives, although the Resuscitation Council (UK) published a report in 1996 with recommendations for practice and training. ${ }^{6}$

This study had two aims: first, to determine whether bereaved next of kin felt they would like to have been present in the resuscitation room during the attempted cardiopulmonary resuscitation of their relative; and second, to evaluate their knowledge and experience of what is involved in cardiopulmonary resuscitation.

\section{Methods}

The next of kin - as stated on the accident and emergency card - of patients over the age of 16 years who had died after unsuccessful cardiopulmonary resuscitation during a nine month period in the accident and emergency (A\&E) department of an inner city teaching hospital was contacted after a minimum interval of 